\title{
Women's Participation in Nigeria's Industrial Development Process: Obstacles and Options for Change
}

\author{
Grace Reuben Etuk $^{1}$, Felicitas Gabriel Coker $^{1}$ \& Abdul Joshua Ogrimah ${ }^{1}$ \\ ${ }^{1}$ Department of Sociology, University of Calabar, Calabar, Cross River State, Nigeria \\ Correspondence: Grace Reuben Etuk, Department of Sociology, University of Calabar, P.M.B. 1115 Calabar, \\ Cross River State, Nigeria. Tel: 234-80-3475-9142. E-mail: graycetuk@yahoo.com
}

Received: September 23, 2014

Accepted: October 15, 2014 Online Published: November 23, 2014

doi:10.5539/jsd.v7n6p168

URL: http://dx.doi.org/10.5539/jsd.v7n6p168

\begin{abstract}
Development is a multifaceted phenomenon. In all its forms, it involves the positive transformation of all aspects society, hence the relentless investment of efforts by all societies to achieve it. Achieving development generally, and industrial development in particular, requires the effort of everyone, including women. For Nigerian women, taking up this all important responsibility has been more or less like swimming against the tide, due to the interaction of various social, cultural and biological factors. This paper x-rays the relevance of women to Nigeria's industrial development, drawing attention to some of the obstacles to their optimal and effective participation in the process. Furthermore, the paper explores available options for change, and concluded that only when women are allowed to actively participate in industrial development via the removal of the identified obstacles, that the industrial and other forms of development in Nigeria can take a turn in the direction of meaningful success.
\end{abstract}

Keywords: development, participation, industrial development, women

\section{Introduction}

In Todaro and Smith (2009) development is conceptualized as a 'process involving changes in societal structures, popular attitudes and national institutions as well as economic growth, the reduction of inequality and eradication of poverty'. Development has many dimensions. Industrial development happens to be one of them and can be viewed in terms of advancement and growth in a society's industrial institutions and structures.

Throughout the globe, a country's level of industrial development remains a major prerequisite for its transformation into what can be regarded as a 'developed society'. Nigeria is far from this categorization. The country still falls among the ones ranked as 'developing societies'. Clearly, a key determinant factor of this categorization is the country's level of industrial development, which is still in its infancy.

Achieving industrial development in Nigeria is an issue that has been of utmost importance to successive governments in the country. The task involved requires the efforts of all and sundry, especially if meaningful progress must be recorded. Women as an important population group, constituting up to half of the nation's population are certainly stakeholders in Nigeria's development at all levels, and so have a part in efforts targeted at the country's industrial development. History presents clear evidence that given the platform, Nigerian women add recognizable value to the country's development process. Unfortunately, their efforts are often marred by a myriad of societal forces.

Notwithstanding, the situation is not entirely hopeless, given that with the right measures in place, the deterring societal forces can be fought off. There is thus need to provide necessary institutional backing for women at all levels to enable them surmount the daunting challenges society and culture place in their way. The role of government, women organizations and the media are of peculiar relevance in paving way for the desired changes. With structural supports from these institutions, women can secure more meaningful positions in the industrial future and landscape of the Nigerian society.

\section{Women and Development: Theoretical Analysis}

Development is a multidimensional and topical phenomenon that constitutes a focal point of most social science discourse and debates. One aspect of these debates that has attracted wide attention is the issue of women's role in development. Frankly, not all the intellectual arguments are in alliance with the viewpoint women have roles 
in development. One theoretical approach having this stance is the Welfare Approach. Being among the oldest of the approaches to women and development (Charles, Ikoh, Charles \& Ita, 2009); the Welfare Approach to women and development as analyzed by Molyneux (1985) views women rather as passive recipients of development. Women's biological and cultural roles in child bearing and child rearing form the bases for this argument by scholars who share this theoretical position. The theory goes hand in hand with the modernization theory in assuming that the benefits of development will only trickle down to women. This has led to a number of heavy criticisms being raised against the Welfare Approach; the major ones being that it has a distorted and detrimental view of women's efforts, and promoted dependency rather than self-reliance among them.

Other theories have emerged which not only challenged the position of the Welfare Approach, but also tend to be more radically supportive of women's participation in development. One of such theories is the Human Resource Approach. This approach recognizes both the productive and reproductive roles of women as overall features of development, proposing that development at its highest level cannot be achieved without the active participation of women (Synder \& Tadesse, 1995). The approach draws attention to the fact that women make up a large proportion of the productive human resources in society and challenges them towards self-development to enhance their positioning for participation at all levels of societal development. The stance of the Human Resource Approach thus debunks notions of women as mere recipients of development benefits, leaving no doubt that development can only be meaningful when women are actively involved.

\section{Reflections on Women's Participation in Nigeria's Industrial Development Process}

Participation in development according to Todaro and Smith (2009:570) is simply 'a say in development policies by the people most affected by them'. It is not only a means of furthering developmental goals, but also constitutes one of the foremost ends of development itself.

In Nigeria, just like many other parts of the world, women constitute up to half of the total human population. As such, efforts and policies targeted at development have direct or indirect impact on them, hence the need for them to be part of the group that should and must have a say or participate in development. Besides, as Todaro and Smith (2009) stressed, genuine and full participation by development beneficiaries minimizes setbacks and makes for the achievement of greater and better results in the development process. Since women are part of the beneficiaries of development, their roles are therefore central to the achievement of the overall goals of development. Although early theoretical thinking and debates did not assume this position, more recent developmental theorizing have been strongly supportive of women's involvement in development at all levels.

In the case of Nigeria, women's roles are cardinal in the country's developmental efforts at all levels. Like other women throughout the globe, Nigerian women's biological function in child bearing puts them at the centre of supplying the human population needed to initiate and sustain industrial development. In Sills (1968) cited in Etuk (2007), it is noted that a key requirement for industrialization is a steady supply of human resources to form the needed labour force. Essien (2005) maintains that the special importance of human resources in development process is hinged on the fact that it takes humans to plot the direction of development and to harness other resources needed for the process. Since the supply of human resources depends very much on the procreative role of women, it therefore makes Nigerian women of invaluable relevance to the country's industrial development.

Maslow (1958) in his hierarchy of needs identified food as the foremost need of man. It is not in doubt that without food man's survival faces threat. The labour force that makes industrial development possible requires adequate nutrition to both safe guard their health and supply the energy they need for work. Availability of food makes this possible. Nigerian rural and even urban women are major stakeholders in the areas of food production and supply, as well as food security. Altogether, they form about $90 \%$ of the work force in food processing (Agbola, 1990). For the rural women, they have limited options when it comes to means of survival. As such, for many of them farming is the main occupation. They form as much as $60 \%$ of the agricultural/farming population in Nigeria (Mijindadi, 1993). Many of them are involved in land clearing, tilling and weeding, as well as preservation of food crops. They take the lead in the planting and harvesting of popular Nigerian food crops like cassava, vegetables, melon, pepper, okro, cocoyam; and in some communities, even yam. Furthermore, as Mabogunje (1991) observed, all over Nigeria especially in the South, periodic markets are held every fourth, fifth or eight day in rural communities where these food items and even cash crops are conveyed for sale by the rural women. Getting these food items to the reach of the population and indeed the labour force in urban areas usually rests on the shoulders of the urban women. They make their way to these periodic markets popularly described as 'bush markets' or 'ahia ime ohia' (among the Ibos) and 'urua esit ikot' (among the Efiks and Ibibios). There, they purchase these food items, many times through extremely deplorable means of 
transportation. By so doing, they become the 'middle men' and the means through which the entire urban populace including the urban work force can access the needed food items. Unarguably, this crucial role of women in making food available and secure for the teeming urban work force makes them priceless to Nigeria's industrial development.

Besides their reproductive and food production roles, women also have productive functions in industrialization and industrial development. In the past century, their participation in paid labour force has risen considerably (Giddens, 2006). Consequently, both in Nigeria and the rest of the globe, they make up a recognizable proportion of labour force. In the case of Nigeria, as at 2010 , women constituted $42.84 \%$ of the nation's work force (www.tradingeconomics.com Retrieved $12^{\text {th }}$ August, 2014). This implies that across all occupations and industries, they also undertake industrial work activities like their male counterparts to facilitate industrial development.

Women's participation in industrial work force in Nigeria is particularly relevant because they still provide cheap sources of labour. Onah (1996) maintains that labour intensive industries find them very useful because of their willingness to accept low wages. Moreover, as Savane (1984) pointed out, they are known to have patience and aptitude for tedious work, and according to Hamman (1979) in Onah (1996) they are more submissive, with a kind word being enough to cheer them up and increase their productivity. Agreeably, these qualities are of huge value for productivity in any industrial work setting.

Lastly, in Nigeria, especially in the Western part of the country, some handicrafts like pottery, tie and dye, as well as black soap production are completely dominated by women. In Oderinde (1996) pottery and tie and dye were identified as making up a considerable proportion of the small and medium scale industries in Abeokuta, Ogun State. Olajumoke's (1994) survey on small scale industries found that out of the 256 small scale industries in Abeokuta, 148 of them (or 57.81\%) were tie and dye and pottery. So crucial are these handicrafts in this State that they have become part of the State Government's industrialization focus (Oderinde, 1996). The centrality of women in these and similar small scale industries goes further to underscore their relevance to Nigeria's march to industrialization and indeed industrial development.

\section{Obstacles to Nigerian Women's Participation in Industrial Development}

A number of Nigerian women like late Dora Akunyili, Grace Alele-Williams, Obiageli Ezekwesili, Dieziani Allison-Madueke, Mariam Babangida, Ngozi Okonjo-Iweala and a host of others who were given the platform, did record developmental strides that pushed Nigeria to global prominence. The diligence and excellence these women displayed in handling their various developmental responsibilities are clear indications that Nigerian women have the potentials to add value to every aspect of the country's development process. With regards to industrial development, as already noted, Nigerian women's roles are key to furthering the process. However, the current reality is that their level of involvement is still minimal and way below that of men. This leads to these crucial questions: why are women still performing below capacity and expectation in the processes geared towards achieving industrial development in Nigeria? What societal, cultural or biological factors obstruct their full participation in the industrial development process in Nigeria?

Indeed, countless factors impede women's optimal involvement in Nigeria's industrial development process. Foremost among such factors is their biological role in procreation. Although this particular function is of relevance to industrial development in supplying human resources, the reality remains that issues relating to pregnancy, child-bearing and child-rearing present far-reaching responsibilities to women. For many women, the period of pregnancy and child bearing are characterized by a slow-down in their work career and participation in workforce. During this period, majority of women are often associated with work irregularities like lateness, absenteeism, geographical immobility etc., occasioned by pregnancy related health challenges or the arduous task of child care. Some even out rightly quit their jobs for a period in order to adequately cater for their children until they reach certain ages. Without doubt, situations like these undermine their work career, labour force participation and productivity for those who are courageous enough not to exit the work force.

Another impediment to women's involvement in Nigeria's industrial development is the male dominated nature of the Nigerian society. This system of male dominance, known as patriarchy, makes it that matters like land ownership and inheritance are centered on men. Women hardly own lands and they are often denied right to inheritance especially when it comes to landed property. These greatly hamper their chances of raising capital from these sources for small and medium scale enterprises. Consequently, the small and medium scale enterprises sector which is pivotal to the industrial buildup of developing economies like Nigeria (Etuk, Etuk \& Baghegbo, 2014) is dominated by men with Nigerian women's involvement and contribution being very negligible. 
Coon (1986) drew attention to the countless subtle pressures by society - parents, peers and cultural forces - that urge boys to 'act like boys' and girls to 'act like girls'. This is gender socialization and constitutes another major force causing Nigerian women to lag behind in efforts geared towards pursuing Nigeria's industrial development Cultural definitions of maleness and femaleness make it that boys and girls are socialized along gender lines. Girls are socialized to take up roles designated by society as 'female roles' while boys are socialized to take up roles culturally prescribed as 'male roles'. Unfortunately for women, the supposed 'male roles' provide men with opportunities to engage in tasks that have more relevance to the industrial scene, thereby giving them an edge over women in that sphere. Only very few women find their way into areas socially designated 'male tasks', the major restraining factor being gender socialization. Supporting this view, Oderinde (1996) stressed that cultural taboos often prevent women from exploring employment areas traditionally dominated by men. The unfortunate consequence has been for women to remain down the ladder in roles that would pave the way for Nigeria's industrial development.

Closely related to gender socialization is the phenomenon of housework. Nigeria is one of those societies where housework is the culturally prescribed role of women (Okolo, 2007). Because housework is labeled 'women's role' in a society like Nigeria, girls are socialized into accepting it as their traditional role. According to Oakley (1979), house work often takes precedence over other roles as the primary role of women and occupies them for about seventy hours per week. This time consuming and tedious nature of housework often keeps women neck-deep in it, giving them little room to effectively engage in other social activities or acquire skills which have direct consequence for Nigeria's industrial development. It is therefore not surprising that many of them excel in their domestic responsibilities but fall short in other areas including development oriented pursuits.

Marriage is another source of set-back to women's involvement in Nigeria's industrial development. According to Haralambos and Heald (1980) a study by Venesse, published in 1962 among 600 school leavers in England revealed that nearly half of them saw marriage as their probable job by the age of twenty-five (25). The trend in the Nigerian society presently is not very different. A slight variation may only be in terms of age but the fact on ground remains that for an average Nigerian woman, marriage means everything. Thus, among Christian adherents for instance, church programmes with promises of making marriages possible, experience very high turn out by women and girls. Unmarried women who have advanced up to certain ages are often treated with little importance by society. As such, some of them who are not 'lucky enough' to be married after certain ages often shift focus from ventures that will give them a platform to contribute meaningfully to development in any of its dimensions to striving to 'settle down'. Some would not opt for certain levels of education or training in order not to 'jeopardize' their chances of getting married. These fears are not unfounded. Negative stereotypes like "men being scared of marrying very educated women" or that "highly educated women do not make good wives' are still very much in place in Nigeria.

For the married ones, the situation is not so better. Many married women terminate their work career soon after marriage. This is because marriage ushers in child birth and child care, making domestic responsibilities to increase. Others do so because their jobs interfere very seriously with their responsibilities at home. In the banking sector for instance, workers can be on their jobs from $7.30 \mathrm{am}$ to $6.00 \mathrm{pm}$. In addition, some jobs require shifts, where workers would some time spend the nights at work. For some women in such jobs, the way out is to resign soon after marriage, in order to give adequate attention to their homes. There is also a group who quit their jobs at the instance of the husbands, especially when the husbands involved have the financial means to cater for the whole family (Anugwom, 2009).

Furthermore, for some women, if their job location is not in the same city where their husbands reside, they simply quit and join their husbands rather than 'compromise' their marriages. For the ones who do not exit the labour market, their jobs suffer considerably. This is because as Oakley (1974) stressed, the housewife - mother role having become institutionalized as their primary role is often retained even with paid employment. Unfortunately, as Oakley further maintained, the role is incompatible with career being a tedious and time-consuming one, hence, the relatively few numbers of female managers and professionals. In summary, important and desirable as marriage is, the institution is indirectly a source of set-back to women with regards to involvement in Nigeria's industrial development.

Illiteracy and low levels of education and training among Nigerian women also limit their capacities and chances of actively participating in the country's industrial workforce. Globally, women are more deprived in education (Todaro \& Smith, 2009). The situation is not different in sub-Saharan Africa and indeed Nigeria, where women and girls form the bulk of the illiterate and poorly educated population group. Yet, education remains the main tool for the impartation of skills and attitude relevant for contribution to development, as well as a critical variable for modern work situation (Anugwom, 2009). Furthermore, citing Ali (2009), Anugwom (2009) 
maintains that education helps to fully develop the potentials of individuals to enable them consummate modern employment opportunities. Given that many Nigerian women are either poorly educated or do not have access to education, the chances are that they will have limited place in modern work force, which is a major driving force for industrial development. The situation is even more appalling in Northern Nigeria where early and forceful marriage is still a prevailing norm. The United Nation reports that out of the 10.5 million children who are out of school in Nigeria, $60 \%$ of them are girls in the North (www.bloomberg.com Retrieved 12-08-14). Certainly, a major contributory factor to this large scale out-of-school situation among girls in Northern Nigeria is early marriage. Early marriage as Okolo (2003) noted can force a girl to shift focus from education and training to making babies and keeping the home. For so many, the issue of education may never be revisited. For others who are daring enough to still further their studies, the venture becomes an uphill task, due to the additional burden of house work and child bearing. The end result will be for them to perform below capacity and in the long run lag behind in the training and skills that position people in the world of work where industrial and other forms of development are steered.

Lastly, the seclusion of women by Islamic adherents in parts of Northern and Western Nigeria also jeopardizes possibilities for affected women to be active participants in Nigeria's pursuit of industrial development. Seclusion in Purdah means limited opportunities for necessary skill acquisition via education, in preparation for the world of work generally and industrial work in particular. It also means shutting them out of the various platforms and scheme of events that determine the direction of development in any of its forms.

\section{Options for Change}

The indications are strong that Nigeria women's roles in development generally and industrial development in particular are invaluable. Reflecting on the gains Nigeria recorded with women like Late Dora Akunyili, Ngozi Okonjo-Iweala and the rest participating in development leaves one imagining what losses Nigeria would have counted if these women did not serve the nation. Unfortunately, there is still a sea of Nigeria women with similar or even better potentials and abilities. For most of them, the stumbling blocks to their involvement in development are the factors discussed. How then can women be helped to surmount the obstacles in their way to participating in industrial development?

An important step in achieving success is for some cultural practices to be overhauled. Culture is a creation of man as such is subject to alteration. The mere fact that certain aspects of culture deter an important segment of the society like women from adding value to society calls to question the relevance of such cultural elements, demanding necessary adjustments to enable women freely express their capabilities with respect to industrial development.

Apart from cultural reformation, institutional and corporate support from government, women organizations and the media will go a long way to facilitate the needed change. On the part of government, the needed support can be in form of:

- Designing and establishing legal frameworks that provide women equal platform as men to make necessary contributions to industrial development.

- Ensuring the development and enforcement of affirmative action legislations that provide quotas for increased women's participation in industrial settings and positions.

- Providing grants, buildings women's capacities and supplying other technical supports for female entrepreneurs.

- Designing and implementing policies aimed at removing all forms of social and cultural barriers to women's autonomy and empowerment.

- Promoting female literacy and redesigning curricular for proper education, to better women's chances in the industrial sphere.

Women organizations can also support by:

- Building and reinforcing self-confidence and positive self-images in women via enlightenment programmes to boost their effectiveness in all spheres of development.

- Providing avenues for the sharing and exchange of information and experiences among women on ways of fostering women's involvement in industrial development.

- Embarking on campaigns and public enlightenment programmes aimed at eliminating discriminatory practices limiting women's chances of adequately affecting the industrial sector. 
Finally, the media could be a very effective tool in bringing the much desired change by supporting public education and awareness on women's potentials and right to full participation in every aspect of Nigeria's development.

\section{Conclusion}

Industrial development is essential for Nigeria's transformation into a completely modern industrialized society. Meaningful progress in this direction cannot be achieved with a crucial population segment like women being left out. They must be carried along, since they have all the potentials to add value to developmental pursuits. Besides, as beneficiaries of development, it is proper for them to be involved in initiating and executing the process.

Beyond merely allowing women to participate in industrial development, the factors that constitute obstacles to their meaningful involvement in the process must be adequately addressed. The roles of government, women's organizations and the media have been identified as being of immense relevance in this regard. With these institutions taking the right measures and putting the necessary machineries in place, Nigeria's quest to become an industrialized nation will be far from being a mirage.

\section{References}

Agbola, T. (1990). The Role of Women in Housing Development. Ibadan: CURP, University of Ibadan.

Anugwom, E. E. (2009, April). Women Education and work in Nigeria. Educational Research and Review, 4(4), $127-134$

Charles, J. O., Ikoh, M. U., Charles, A. O., \& Ita, M. E. O. (2009, January). Women-directed approaches to Employment generation in Nigeria: A Review of Theoretical and Practical options. Nigerian Journal of Social and Development Issues, 6(1), 43-63.

Coon, D. (1986). Introduction to Social Psychology: Exploration and Application. New York: West Publishers.

Essien, E. E. (2005). Empowering women for Development: A Business Perspective. In I. V. O. Modo (Ed.), Sustainable Development in Africa - A book of Readings (pp. 238-251). Uyo: Cultural Research Publishers.

Etuk, G. R. (2007). Rural Women and Sustainable Development in Nigeria. International Journal of Multidisciplinary Scholarship, 1(1), 30-37.

Etuk, R. U., Etuk, G. R., \& Baghegbo, M. (2004). Small and Medium Scale Enterprises (SMEs) and Nigeria's Economic Development Mediterranean. Journal of Social Sciences, 5(7), 656-662.

Haralambos, M., \& Heald, R. M. (1980). Sociology: Themes and Perspectives. Oxford: Oxford University Press.

Magbogunje, A. L. (1991). Women in Business and Agribusiness in Nigeria. Mimeograph. Ibadan: Wemilore press.

Maslow, A. H. (1958). Motivation and Personality. New York: Harper and Row.

Mijindadi, N. B. (1993). Agricultural Extension: Experience for Women. Paper presented at the $13^{\text {th }}$ World Bank Agricultural resource Management. Washington, D. C., pp. 20-25.

Molyneux, M. (1985). Mobilization without emancipation Women's interest, state and revolution in Nicaragua. Feminist Studies, XI(2), 41-53.

Oakley, A. (1974). Housewife. London: Allen Lane.

Oakley, A. (1979). The Sociology of Housework. Oxford: Basil Blackwell.

Oderinde, J. A. (1996). Women in a sustainable home project: The case of Pottery, Tie-Dye in Abeokuta Ogun State (Edited by Y. Oruwayi, pp. 269-274).

Okolo, G. U. (2003). Violence against Women. Calabar: Baye Communication.

Okolo, G. U. (2007, October). Culture, Women and Sociopolitical Development in Nigeria. International Journal of Development and Management Review, 2(1), 80-87.

Olajumoke, O. O. (1994). Structure of small scale industries in Abeokuta South Local Government: Focus on Tieing and Dyeing. Unpublished Dissertation, The Polytechnic, Ibadan.

Onah, F. O. (1996). Women and employment situation in Nigerian urban environment. In Y. Oruwari (Ed.), Women Development and the Nigerian Environment (pp. 231-239). Ibadan: Vantage Publishers. 
Savane, M. A. (1984). Women as industrial wage-earners and changing family structures in Africa. In Women on the Move UNBSCO.

Synder, M. C., \& Tadesse, M. (1995). African Women and Development. London: Zed Books.

Todaro, M. P., \& Smith, S. C. (2009). Economic Development. London: Addison Wesley.

\section{Copyrights}

Copyright for this article is retained by the author(s), with first publication rights granted to the journal.

This is an open-access article distributed under the terms and conditions of the Creative Commons Attribution license (http://creativecommons.org/licenses/by/3.0/). 